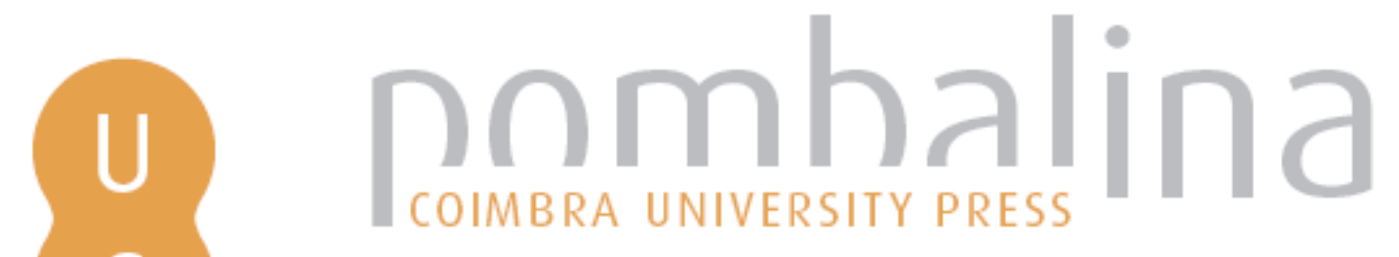

\title{
Mostrar Carlos Seixas
}

Autor(es): $\quad$ Cardoso, José Maria Pedrosa

Publicado por: Imprensa da Universidade de Coimbra

URL

persistente: URI:http://hdl.handle.net/10316.2/32513

DOI: $\quad$ DOI:http://dx.doi.org/10.14195/978-989-26-0409-1_2

Accessed : $\quad$ 26-Apr-2023 15:59:29

A navegação consulta e descarregamento dos títulos inseridos nas Bibliotecas Digitais UC Digitalis, UC Pombalina e UC Impactum, pressupõem a aceitação plena e sem reservas dos Termos e Condições de Uso destas Bibliotecas Digitais, disponíveis em https://digitalis.uc.pt/pt-pt/termos.

Conforme exposto nos referidos Termos e Condições de Uso, o descarregamento de títulos de acesso restrito requer uma licença válida de autorização devendo o utilizador aceder ao(s) documento(s) a partir de um endereço de IP da instituição detentora da supramencionada licença.

Ao utilizador é apenas permitido o descarregamento para uso pessoal, pelo que o emprego do(s) título(s) descarregado(s) para outro fim, designadamente comercial, carece de autorização do respetivo autor ou editor da obra.

Na medida em que todas as obras da UC Digitalis se encontram protegidas pelo Código do Direito de Autor e Direitos Conexos e demais legislação aplicável, toda a cópia, parcial ou total, deste documento, nos casos em que é legalmente admitida, deverá conter ou fazer-se acompanhar por este aviso.

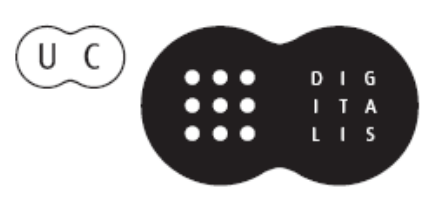




\section{J. M. PEDROSA CARDOSO}

Coordenação

J. M. PEDROSA CARDOSO • ANTÓNIO FILIPE PIMENTEL MANUEL CARLOS DE BRITO • JOSÉ LÓPEZ-CALO JOSÉ EDUARDO MARTINS • ABÍLIO QUEIRÓS

Autores

\section{Carlos Seixas, \\ de Coimbra}

Ano Seixas

Exposição Documental

Coimbra I mprensa da Universidade $\quad 2004$ 
(Página deixada propositadamente em branco) 
J. M. PEDROSA CARDOSO

Coordenação

J. M. PEDROSA CARDOSO • ANTÓNIO FLLIPE PIMENTEL

MANUEL CARLOS DE BRITO • JOSÉ LÓPEZ-CALO

JOSÉ EDUARDO MARTINS • ABÍLIO QUEIRÓS

Autores

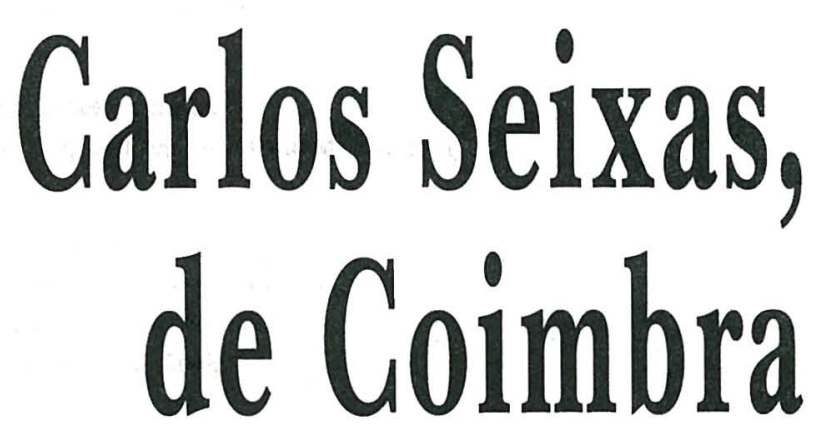

Ano Seixas

Exposição Documental

Coimbra - Imprensa da Universidade $\quad 2004$ 


\section{Coordenação editorial}

Imprensa da Universidade de Coimbra

\section{Concepção gráfica}

António Barros

\section{Paginação}

Victor Hugo Fernandes

\section{Créditos fotográficos}

p. 98 José Manuel Vasconcellos, p. 99 e 100 Varela Pécurto

\section{Execução gráfica}

Imprensa de Coimbra, Lda.

Couraça dos Apóstolos, 126

3000-372 Coimbra

\section{ISBN}

972-8704-33-X

\section{Depósito Legal}

\section{$218421 / 04$}

(C) 2004, Imprensa da Universidade de Coimbra

Obra publicada com o patocínio do GRUPO AMORIM:

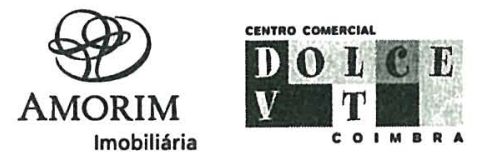

Apoio de:

Reitoria da Universidade de Coimbra

Biblioteca da Universidade de Coimbra

Arquivo da Universidade de Coimbra

Faculdade de Letras da Universidade de Coimbra 


\section{Mostrar Carlos Seixas \\ José Maria Pedrosa Cardoso \\ (Universidade de Coimbra)}

A Música não é cultura unívoca no teatro das nações. Aceitar a variedade das músicas na pluralidade das culturas é hoje, mais que nunca, um imperativo do saber e do bom senso. Despertando do sonho romântico de uma linguagem musical unificadora do universo, resta-nos a certeza do diálogo das culturas e, com elas, das gramáticas musicais que é preciso conhecer e estudar. À escala planetária, com a proximidade e a rapidez do progresso, mas também ao ritmo de uma Europa unificada.

E não apenas nas grandes linhas que definiram na raiz a grande música europeia a partir dos renascimentos sucessivos, na referência natural ao(s) berço(s) da civilização do Ocidente, em oposição a diferentes estéticas do som e do seu disfrute em outras civilizações distantes no tempo e no espaço. Importa referir, cada vez mais, as singularidades que, também no mundo da Música, constituem a própria essência da Europa. Quem disse que há apenas uma Música europeia ou apenas uma Música hispânica nos limites que a Geografia unificou?

É assim que não vale mais a identificação do «Scarlatti português» atribuído a Carlos Seixas, do «Mozart português» dito de João de Sousa Carvalho, ou de outras colagens pretensamente niveladoras de mérito ou de valor estético por aproximação. Como todos os povos, Portugal tem os seus nomes próprios, os cérebros e os artistas que nasceram na identidade das suas fronteiras. É aqui que eles se afirmaram no papel que lhes coube, que mereceram ou conquistaram, fazendo uma história própria, contribuindo 
para a mesma, independentemente do seu nível social ou da sua conviç̧ão religiosa. Nomes como D. Diniz, o Trovador, Pêro do Porto, Manuel Mendes, Marcos Portugal, Domingos Bomtempo, por exemplo, justificam inteiramente o nome de Carlos Seixas: um filho da nação, um talento aproveitado e merecido pelo meio e pelo tempo em que viveu. Porventura um pequeno, um grande génio. Mas porque é necessário comparar o génio barroco, ou romântico, português se o movimento barroco, ou romântico, foi diferente em Portugal, na Itália ou na Alemanha?

Com liberdade e autonomia, sem complexos culturais, é urgente falar do que é nosso e, por isso, iluminar mais e escrever melhor o nome de Carlos Seixas. Que se sabe, afinal, deste nome? Pode-se bem dizer que, entre os músicos que fizeram história em Portugal, ele é dos mais conhecidos, pelo menos desde 1933. Nesse ano, em 13 de Fevereiro no Teatro de S. Carlos, tocou-se pela primeira vez nos tempos modernos, graças ao Dr. Ivo Cruz e ao professor Macário Santiago Kastner, o Concerto para Cravo e Orquestra de Carlos Seixas. A partir de então, o nome de Seixas tornou-se conhecido em todo o mundo, porventura antes que em Portugal: as primeiras edições da sua música não se devem a um musicólogo estrangeiro e a uma editora alemã? Pode-se dizer que Portugal despertou finalmente para Carlos Seixas na segunda metade do século XX. Espera-se que o tricentenário contribua para despertar a consciência e os interesses. Neste momento, cumpre mostrar Seixas.

Mas será possível ver Carlos Seixas? O músico de Coimbra não foi suficientemente falado, a sua música não foi ouvida, este ano pelo menos, quase até à impertinência? Em Coimbra, por exemplo, quantas vezes foi possível ouvir a sua Missa em Sol M.? Parodiando Barbosa Machado, poder-se-ia dizer que, só em Coimbra, se ouviram este ano, repetidas embora, mais de 700 sonatas de Carlos Seixas. Que significa, mesmo assim, mostrar uma arte que é de ouvir? Não se trata apenas da dimensão interdisciplinar: é que a Música, a que se ouve com prazer, é também arte de escrever, traduzir, gravar. $\mathrm{E}$ depois, quando se ama, não se pára mais: o mundo dos porquês é sempre curto e o mistério não tem fundo. Por tudo isso, pareceu bem mostrar o mundo de Seixas em Coimbra: o que ele aqui fez, o que para aqui trouxe ou fez trazer.

Por isso, Carlos Seixas, de Coimbra. Porque nesta cidade nasceu, aqui foi mimado pelas musas, porque aqui ensaiou as suas escalas, as suas melodias e os seus ritmos. Cresceu em Coimbra, à sombra das igrejas - da 
Sé, de Santa Cruz, das capelas da Universidade e dos numerosos Colégios universitários. Não se sabe ao certo porque trocou as ninfas do Mondego pelas Tágides. Em Lisboa afirmou-se e continuou a crescer, entre os maiores. Mas a Coimbra voltou sempre, como todos, justificando, agora com novos laços familiares, a glória de um nome reconhecido.

Continuou a encantar no velho órgão da Sé e nos novos órgãos da cidade - o de Santa Cruz e o da Capela de S. Miguel da Universidade. E o seu nome reconhecido finalmente, foi depressa escrito nas cópias da sua música, que os Cónegos de Santa Cruz fizeram questão de possuir. Se não foi ali que o jovem José António aprendeu tudo, foi lá especialmente admirado através de, pelo menos, cinco livros de música que o grande bibliotecário D. Pedro da Encarnação registou para a posteridade. Desses mesmos livros, após os desastres da História, a Universidade conserva ciosamente apenas dois, ainda fonte essencial para o conhecimento da obra para tecla do compositor de Coimbra.

Mas há ainda os segredos do seu nome, da sua história familiar, nos documentos que a Universidade igualmente guarda. Sabia-se alguma coisa, mas era preciso adivinhar o resto (e alguns o fizeram romanticamente). Os dados arquivísticos de Coimbra, essenciais para o conhecimento da sua pessoa, mas dispersos e fragmentários, são agora melhor apresentados e explicados. A partir de agora, o nome familiar de José António Carlos de Seixas aparecerá mais próximo de uma realidade, que possivelmente nunca se conhecerá plenamente.

Ali estão também as imagens possíveis dos locais que ele habitou, os contornos geográficos e as pessoas que se cruzaram no seu caminho. É verdade que há mais mundos, mais imagens e mais documentos que completariam o quadro da vida e da obra de Seixas. Mas, por todas as razões, aceite-se o limite de Coimbra - os documentos da Universidade e dos seus Doutores - e cumpra-se o dever de os mostrar.

Não se esgota em Coimbra o pouco que existe sobre a vida e obra de Carlos Seixas em Portugal. Ficam de fora a maioria dos manuscritos: todos os de música vocal, que é preciso procurar nos arquivos de Viseu, Lisboa, Elvas e Évora, e ainda vários fundamentais com a sua música instrumental, que se conservam na Biblioteca Nacional e na Biblioteca da Ajuda. Apresentando-se apenas, por natural exiguidade de meios, os manuscritos de Coimbra, está-se a afirmar a justeza desta iniciativa na terra natal do compositor, expondo-se com a seriedade necessária o que é ainda documentação 
única. São os dois preciosos livros, os MM 57 e 58, com um total de 58 Sonatas, algumas das quais como fonte única para a fixação do corpus da sua música de teclas, mas são também alguns Minuetes dispersos pelos MM 61 e 64, que esta exposição pela primeira vez identifica. O restante material exposto, edições modernas e bibliografia passiva, é tudo o que a Universidade, com as suas bibliotecas e os seus professores, pode oferecer ao estudioso.

Acto académico na sua génese, esta mostra é também afirmação de uma consciência de valor multiplicado: da História, da Estética e do Património. Para que, vendo, ninguém diga que não sabe e, ouvindo, ninguém diga que não gosta. 
(Página deixada propositadamente em branco) 


\section{Série}

\section{Documentos}

Imprensa da Universidade de Coimbra

Coimbra University Press

2004

- U

C • 